\title{
Profiling individual clinical responses by high- frequency serum neurofilament assessment in MS
}

Katja Akgün, MD, Nicole Kretschmann, Rocco Haase, Undine Proschmann, MD, Hagen H. Kitzler, MD, Heinz Reichmann, MD, PhD, and Tjalf Ziemssen, MD, PhD

Neurol Neuroimmunol Neuroinflamm 2019;6:e555. doi:10.1212/NXI.0000000000000555

\author{
Correspondence \\ Dr. Ziemssen \\ Tjalf.Ziemssen@ \\ uniklinikum-dresden.de
}

\section{Abstract}

\section{Objective}

To evaluate individual neurofilament light chain (NfL) variation over the time of disease course and the potential of NfL measurement to predict treatment response in patients with MS.

\section{Methods}

We investigated 15 patients with MS after immune reconstitution treatment with alemtuzumab (ATZ). Monthly serum NfL (sNFL) measurements were correlated with Expanded Disability Status Scale (EDSS), MRI, and relapse activity over an observational period of up to 102 months.

\section{Results}

Before ATZ, sNfL was significantly increased in correlation with previous relapse/MRI activity. After ATZ, sNfL decreased quickly within the first 6 months. In patients classified as NEDA-3, sNfL declined and persisted at an individual low steady-state level of $<8 \mathrm{pg} / \mathrm{mL}$. During followup, 34 sNfL peaks with a $>20$ fold increase could be detected, which were associated with clinical or MRI disease activity. Even patient-reported relapse-suspicious symptoms, which have not been confirmed because relapses were accompanied by $\mathrm{sNfL}$, increase, proposing sNfL assessment as a marker for relapse activity. sNfL started to increase earliest 5 months before, peaked at clinical onset, and recovered within 4-5 months. sNfL presented at higher levels in active patients requiring ATZ retreatment compared with responder patients. During 2 documented pregnancies, sNfL was at a low level, whereas a postpartum transient sNfL increase was seen without any signs of activity.

\section{Conclusions}

This study applied a long-term high-frequency sNfL assessment in an ATZ-treated cohort, allowing a holistic profiling on the individual level and highlighted that sNfL can eminently complement the individual clinical and MRI monitoring in clinical practice.

\footnotetext{
From the Center of Clinical Neuroscience (K.A., N.K., R.H., U.P., T.Z.), University Hospital, Dresden, Germany; Department of Neuroradiology (H.H.K.), University Hospital, Dresden, Germany; and Department of Neurology (H.R.), University Hospital, Dresden, Germany.

Funding information and disclosures are provided at the end of the article. Full disclosure form information provided by the authors is available with the full text of this article at Neurology.org/NN. 


\section{Glossary}

ATZ = alemtuzumab; cMRI = cerebral MRI; EDSS = Expanded Disability Status Scale; Gd + = gadolinium enhancing; IRT = immune reconstitution therapy; NEDA = no evidence of disease activity; NfL = neurofilament light chain; SIMOA = single molecule array technology; $\mathbf{s N f L}=$ serum neurofilament light chain; $\mathbf{S S}=$ steady state.

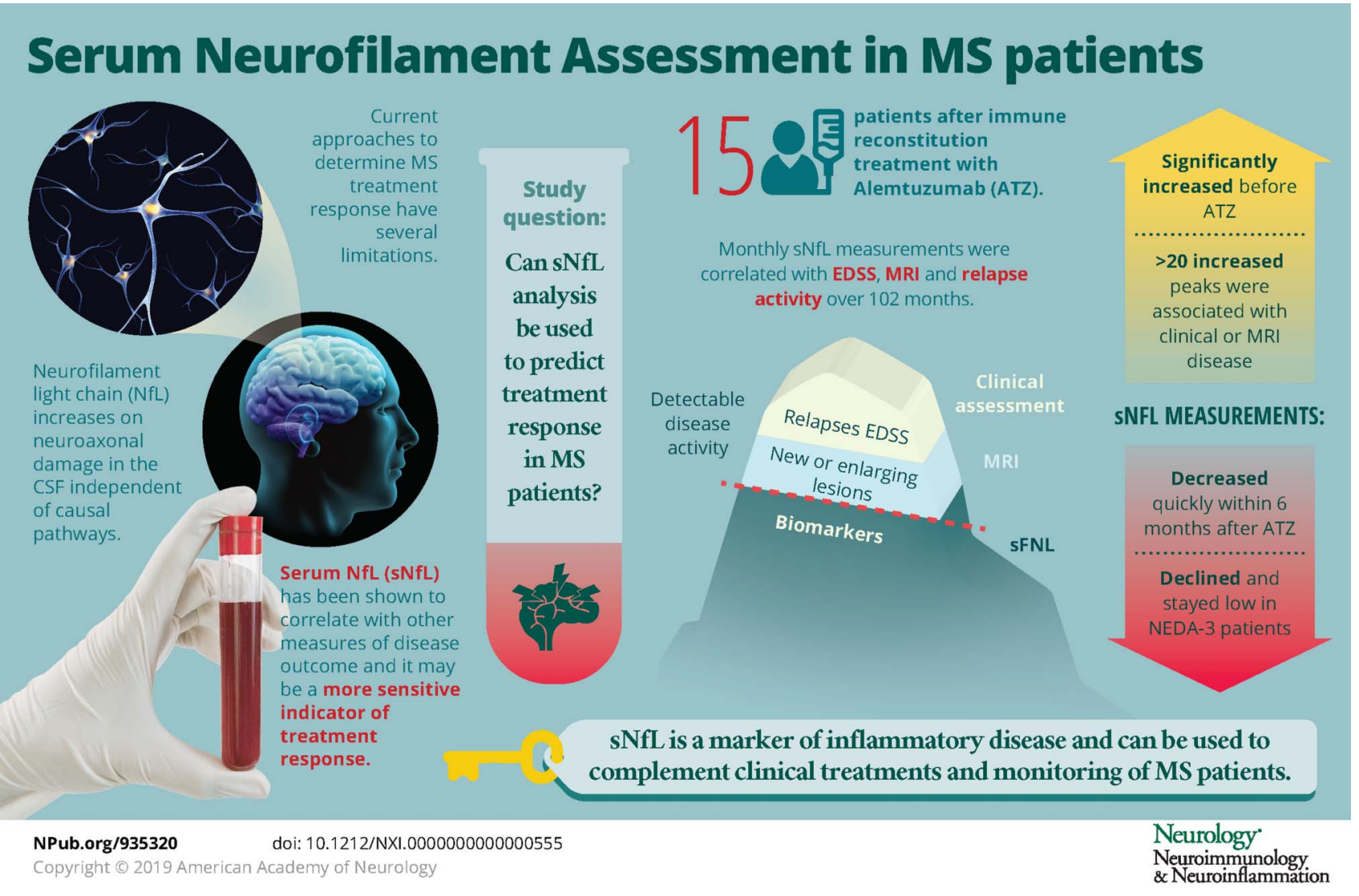

Alemtuzumab (ATZ; Lemtrada, Sanofi) is a humanized monoclonal antibody and represents one of the most effective treatments for active relapsing-remitting MS. ${ }^{1,2}$ ATZ might produce a durable therapeutic response as a consequence of a permanent rebalancing of the immune system. ${ }^{3}$ It has introduced the immune reconstitution therapy as a new therapeutic induction therapy-like concept in MS. ${ }^{4}$ The definition of clinical response profiles after ATZ dosing is crucial to the identification of patients who need retreatment or switching to other therapy. Until now, primarily clinical characteristics such as relapse activity, disability, and repeated MRI analysis have been used to define response profiles to MS treatment. ${ }^{5,6}$ However, this approach has several limitations because even high-frequency clinical and MRI assessment is not sensitive enough to detect all neuroinflammatory and neurodegenerative activity, and additional biomarkers are needed to complement clinical- and MRI-derived information. ${ }^{7}$

In particular, reliable quantification and longitudinal followup evaluation of neuroaxonal damage would be important for assessing MS disease activity, monitoring treatment response, facilitating treatment development, and determining prognosis. The neurofilament proteins that represent one of the main cytoskeletal constitutes in neurons show promise in this context because their levels rise upon neuroaxonal damage not only in the CSF but also in blood, indicating neuroaxonal injury independent of causal pathways. ${ }^{8-10}$ Different studies presented that neurofilament light chain (NfL) is increased in the CSF of patients with clinically isolated syndrome and MS and correlates with MRI activity, disability, and relapse activity. ${ }^{11-16}$ Third-generation (electrochemiluminescence) and particularly fourth-generation (single-molecule array [SIMOA]) assays enable the reliable measurement of neurofilaments throughout the range of concentrations found in blood samples. Previous studies suggest serum (s)NfL as a potential predictive marker for MS disease outcome. ${ }^{13,17-19}$ Nevertheless data and studies are missing that clarify how sNfL measurements develop over time, at relapse, or remission and whether sNfL level may be able to predict treatment response.

In this study, we analyzed individual long-term series of sNfL levels in patients with highly active relapsing-remitting MS after immune reconstitution treatment with ATZ using highfrequency sNfL assessment over a long observational period of up to 102 months. By this approach, we aim to observe sNfL changes in the MS disease course and stratify the 
Table Clinical parameters and sNfL levels before starting ATZ

\begin{tabular}{|c|c|c|c|c|c|c|c|c|c|c|}
\hline Patient & Sex & $\begin{array}{l}\text { Age at } \\
\text { starting } \\
\text { ATZ }\end{array}$ & $\begin{array}{l}\text { EDSS at } \\
\text { starting } \\
\text { ATZ }\end{array}$ & $\begin{array}{l}\text { Last } \\
\text { relapse } \\
\text { before } \\
\text { starting } \\
\text { ATZ [mo] }\end{array}$ & $\begin{array}{l}\text { New T2 } \\
\text { lesions in } \\
\text { MRI at } \\
\text { starting } \\
\text { ATZ [no.] }\end{array}$ & $\begin{array}{l}\text { New Gd + } \\
\text { lesions in } \\
\text { MRI at } \\
\text { starting ATZ } \\
\text { [no.] }\end{array}$ & $\begin{array}{l}\text { No. of } \\
\text { lesions in } \\
\text { MRI at } \\
\text { starting } \\
\text { ATZ }\end{array}$ & $\begin{array}{l}\text { sNfL } \\
\text { before } \\
\text { starting } \\
\text { ATZ [pg/ } \\
\text { mL] }\end{array}$ & $\begin{array}{l}\text { Individual } \\
\text { sNfL at } \\
\text { steady } \\
\text { state [pg/ } \\
\text { mL } \pm \text { SD] }\end{array}$ & $\begin{array}{l}\text { No. of mo when } \\
\text { sNfL steady } \\
\text { sate was } \\
\text { reached after } \\
\text { ATZ }\end{array}$ \\
\hline 1 & $f$ & 39 & 3 & 1 & 0 & 2 & $>20$ & 35.7 & $5.38 \pm 1.17$ & 7 \\
\hline 2 & $f$ & 24 & 3.5 & 4 & 4 & 3 & $>30$ & 19.5 & $4.61 \pm 1.14$ & 2 \\
\hline 3 & $f$ & 25 & 3 & 5 & 0 & 0 & $>10$ & 4.42 & $3.7 \pm 0.8$ & - \\
\hline 4 & $f$ & 44 & 2.5 & 10 & 4 & 5 & $>20$ & 6.89 & $5.56 \pm 1.56$ & - \\
\hline 5 & $\mathrm{~m}$ & 32 & 2.5 & 10 & 2 & 0 & $>20$ & 12.4 & $5.27 \pm 0.71$ & 5 \\
\hline 6 & $\mathrm{~m}$ & 31 & 3.5 & 4 & 7 & 5 & $>20$ & 29.1 & $5.22 \pm 1.17$ & 10 \\
\hline 7 & $f$ & 21 & 1.5 & 5 & 2 & 0 & $>30$ & 3.27 & $2.36 \pm 0.48$ & - \\
\hline 8 & $f$ & 28 & 1.5 & 10 & 2 & 0 & $>15$ & 4.13 & $3.96 \pm 1.52$ & - \\
\hline 9 & $\mathrm{~m}$ & 25 & 1.5 & 6 & 2 & 2 & $>15$ & 4.81 & $3.83 \pm 1.13$ & - \\
\hline 10 & $f$ & 31 & 4 & 2 & 17 & 15 & $>40$ & 23.5 & $5.63 \pm 1.7$ & 6 \\
\hline 11 & $f$ & 45 & 3 & 4 & 1 & 1 & $>10$ & 9.31 & $5.56 \pm 1.04$ & 3 \\
\hline 12 & $f$ & 27 & 1.5 & 15 & 0 & 0 & $>10$ & 1.37 & $4.71 \pm 2.59$ & - \\
\hline 13 & $f$ & 21 & 2 & 14 & 0 & 0 & $>10$ & 6.32 & $3.97 \pm 0.85$ & - \\
\hline 14 & $f$ & 29 & 3 & 3 & 1 & 0 & $>15$ & 5.22 & $4.69 \pm 0.82$ & - \\
\hline 15 & $\mathrm{~m}$ & 36 & 1 & 6 & 0 & 0 & $>20$ & 2.44 & $4.35 \pm 1.14$ & - \\
\hline
\end{tabular}

Abbreviations: ATZ = alemtuzumab; Gd+ = gadolinium enhancing; no. = number; sNfL = serum neurofilament light chain. sNfL before ATZ in bold mark - the significant increased sNfL compared to steady state.

potential to predict disease activity vs remission and treatment response in patients with MS in clinical practice.

\section{Methods}

\section{Patients, collection of clinical data, and blood sampling}

In this pilot study, we included 15 patients with relapsingremitting MS with clinical- and MRI-confirmed highly active disease course (figures $1-5$, table). All patients were treated based on a standardized infusion scheme as described and used in CARE-MS 1 and 2 clinical trials ${ }^{20-22}$ : During the first infusion course, $12 \mathrm{mg} \mathrm{ATZ}$ was infused for 5 consecutive days. During the second course, 12 months later, ATZ was administered for 3 consecutive days. Serum samples were obtained before the first ATZ infusion (baseline, month 0) and then monthly during follow-up for up to 102 months. Clinical parameters including relapse activity and Expanded Disability Status Scale (EDSS) were recorded at monthly respectively three monthly visits. A cerebral (c)MRI was performed every 12 months or more frequently if needed.

ATZ retreatment with an additional course of $12 \mathrm{mg}$ ATZ given for 3 consecutive days was considered when clinical disease activity including relapses appeared or MRI progression was confirmed by new gadolinium-enhancing $(\mathrm{Gd}+)$ lesions and/or 2 new T2 lesions. Definition of no evidence of disease activity (NEDA) is a composition of main outcome measure in treated patients with relapsing-remitting $\mathrm{MS}^{23}$ Criteria for NEDA-3 status were defined as (1) absence of relapses, (2) absence of disability worsening defined by confirmed EDSS progression ( $\geq 1.0$ point increase if the EDSS baseline score was $<5.5$; $\geq 0.5$ point increase if the EDSS baseline score was $\geq 5.5$ ), and (3) absence of MRI progression (no evidence for new $\mathrm{Gd}+$ lesions and/or new $\mathrm{T} 2$ lesions).

\section{Study approval}

The experiments and the study were approved by the institutional review board of the University Hospital of Dresden. All patients gave their written informed consent.

\section{sNfL measurement using single-molecule analysis}

Serum samples were collected monthly and directly stored at $-20^{\circ} \mathrm{C}$ until after preparation because $\mathrm{NfL}$ protein is stable during freezing process. ${ }^{24,25} \mathrm{sNfL}$ measurement was performed using the Advantage NF-Light Singleplex Kit and prepared as defined in the manufacturer's instructions (Quartered, Lexington, MA, Datasheet Quanterix: SIMOA NF-Light Advantage Kit). The SIMOA Human Advantage $\mathrm{NfL}$ assay is a digital immunoassay for the quantitative 


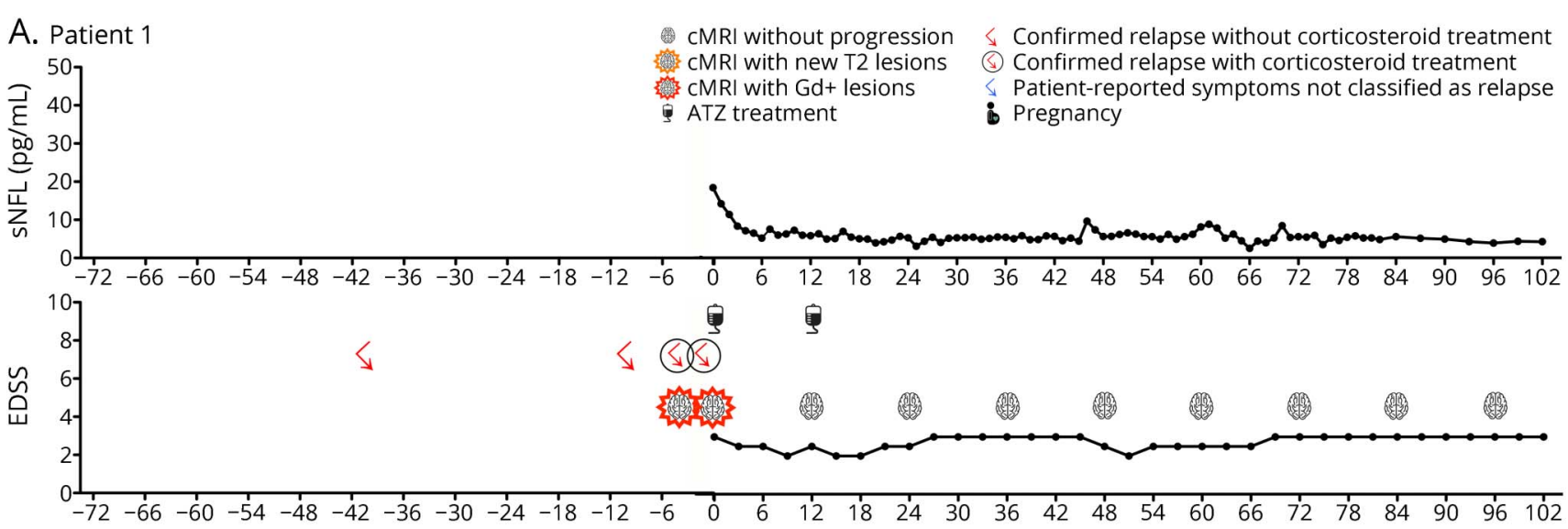

B. Patient 2

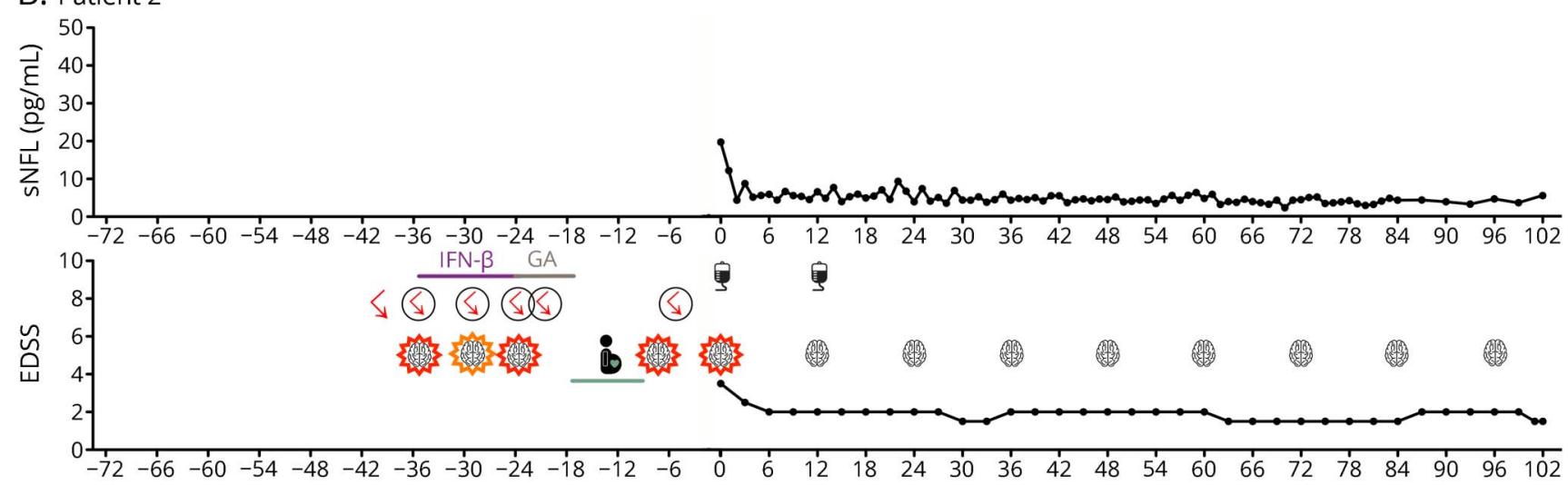

C. Patient 3

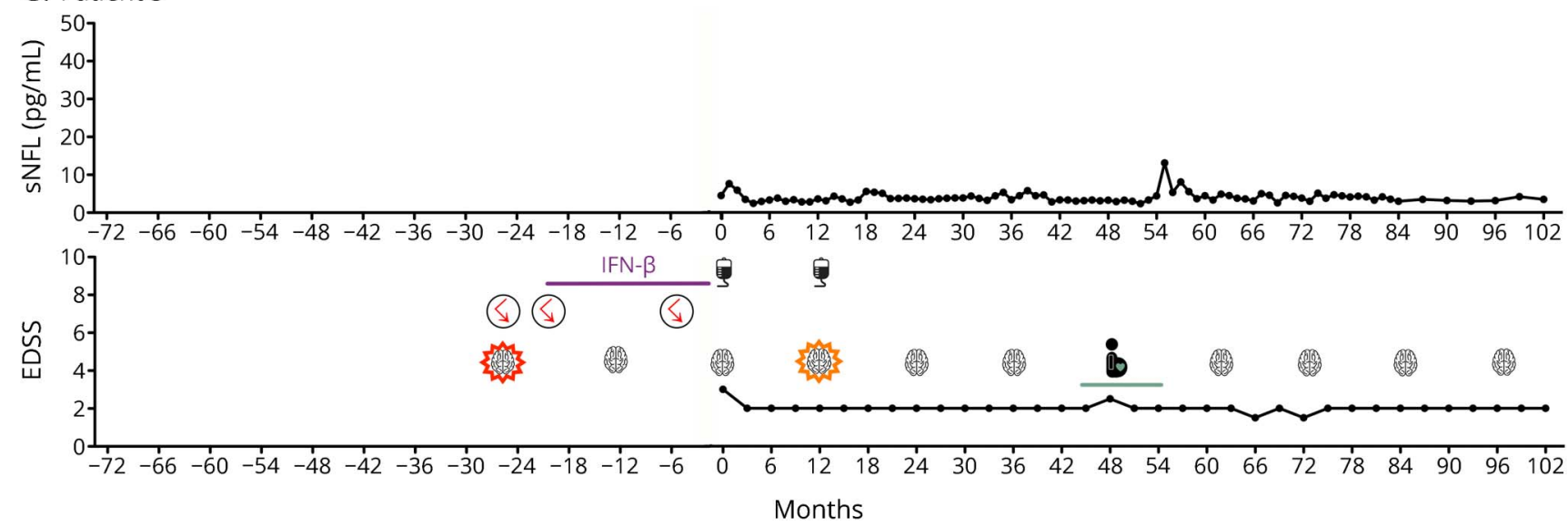

Clinical data and sNfL variation since starting ATZ and during follow-up are presented. Clinical data including relapse activity, MRI activity, and pretreatments are shown for the period before starting ATZ. Since ATZ initiation, a standardized monitoring scheme was performed by evaluation of relapse activity every months, 3 monthly EDSS, and cerebral MRI every 12 months. Patient 1 to 3 (A to C) did receive only the first and the second ATZ infusion cycles. (Patients 1-3; AC) After the first and the second standard ATZ infusion courses, patients presented NEDA-3 status and low level of sNfL in the follow-up. ATZ = alemtuzumab; $\mathrm{CMRI}=$ cerebral magnetic resonance imaging; Gd+ = gadolinium enhancing; $\mathrm{SNfL}$ = serum neurofilament light chain.

determination of NfL and was ran on a Simoa HD-1 instrument (Quanterix). ${ }^{26}$ The antibodies and calibrators used in the assays have been developed by Uman Diagnostics (Sweden) and described previously in their platebased enzyme-linked immunosorbent assay. ${ }^{27}$ Previous reports proved that the newly developed SIMOA technique is the most sensitive to detect $\mathrm{NfL}$ even in lowest concentrations. ${ }^{28}$ Calibrators (8 calibrator points) and diluted serum samples (dilution 1:4) were measured in duplicates. Sample dilution was calculated using the instrument. The lower threshold of quantification was 0.775 $\mathrm{pg} / \mathrm{mL}$. Both the mean intraassay coefficient of variation of duplicates and the mean interassay coefficient of variation were $<10 \%$. 


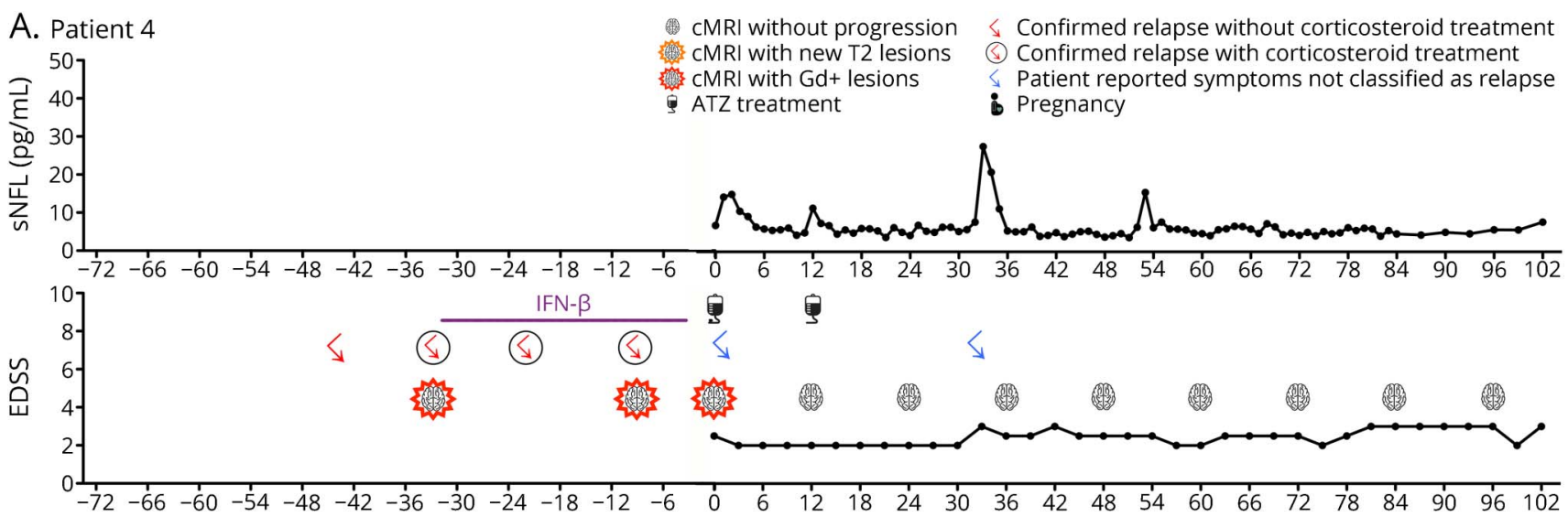

B. Patient 5

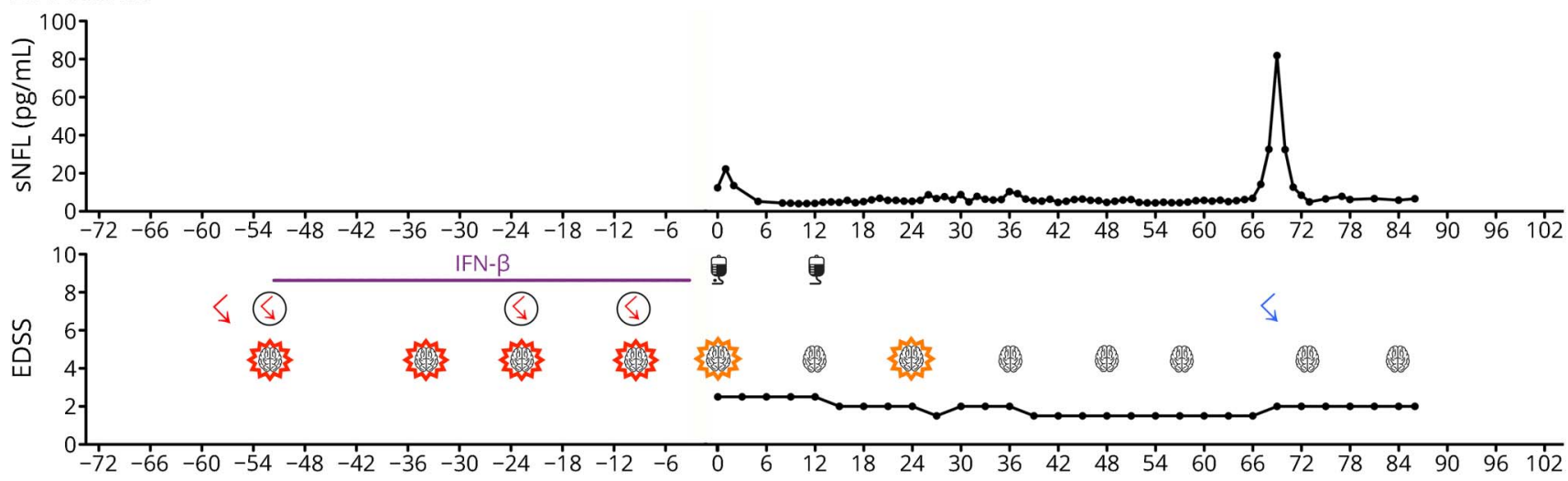

C. Patient 6
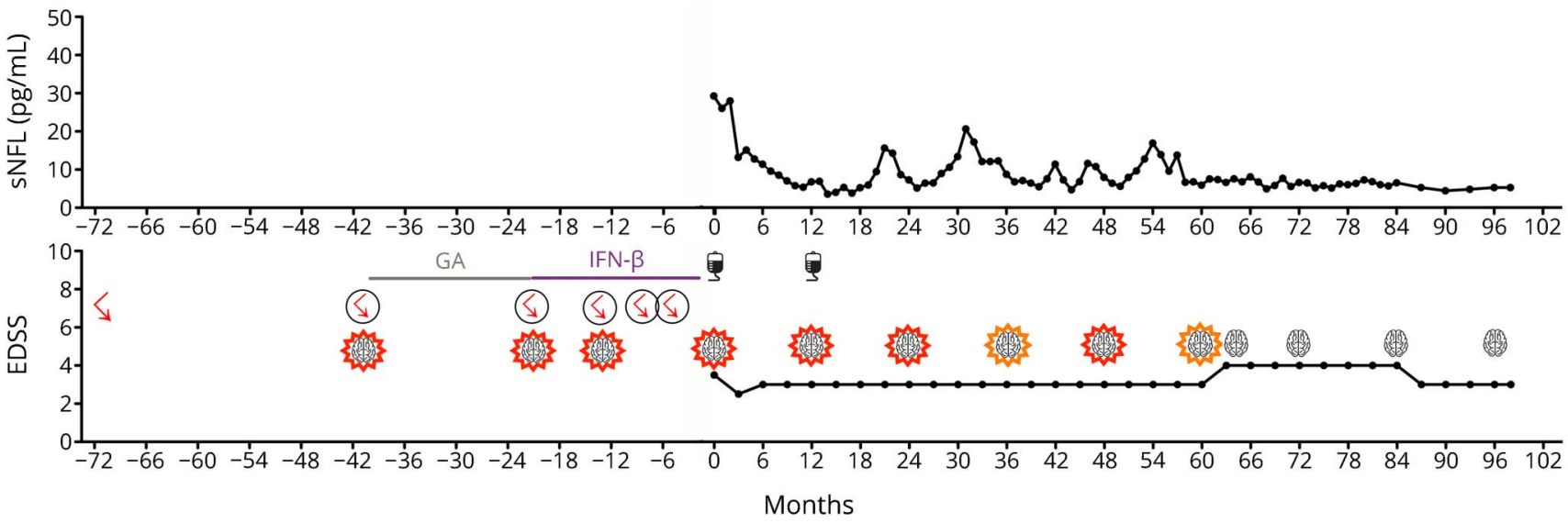

Clinical data and SNfL variation since starting ATZ and during follow-up are presented. Clinical data including relapse activity, MRI activity, and pretreatments are shown for the period before starting ATZ. Since ATZ initiation, a standardized monitoring scheme was performed by evaluation of relapse activity every months, 3 monthly EDSS, and cerebral MRI every 12 months. Patient 4 to 6 did receive only first and second ATZ infusion cycle. (patients 4 and 5) After the first and the second standard ATZ infusion courses, patients presented NEDA-3 status and low level of sNfL in the follow-up. In patient 4 and 5 , sNfL significantly increased at selected time intervals. At these events, the patients presented acute neurologic symptoms that were not classified as acute relapses by the treating neurologist. No corticosteroid treatment was performed and symptoms resolved within weeks spontaneously. (patient 6) After ATZ, no clinical relapses appeared but ongoing disease activity was confirmed by MRI progression, which was paralleled by $\mathrm{sNfL}$ increase. $\mathrm{ATZ}=$ alemtuzumab; $\mathrm{cMRI}=$ cerebral magnetic resonance imaging; Gd+ = gadolinium enhancing; NEDA = no evidence of disease activity; sNfL = serum neurofilament light chain.

\section{Statistical analysis}

An individual steady state (SS) of sNfL levels during stable disease was defined in each patient as mean (SS) \pm SD of all sNfL measurements in the selected period of NEDA (no confirmed relapses, no confirmed EDSS progression defined by increase $\geq 1.0$ for minimum of 6 months, and no
MRI progression). A clinically significant increase in $\mathrm{sNfL}$ was defined as $>([$ mean $[S S]+[3 \times \mathrm{SD}])$ in each patient. Longitudinal data were analyzed by generalized linear mixed models with gamma distribution and log link function because of the right-skewed distribution pattern for the evaluation of sNfL variation over the time. CIs and 


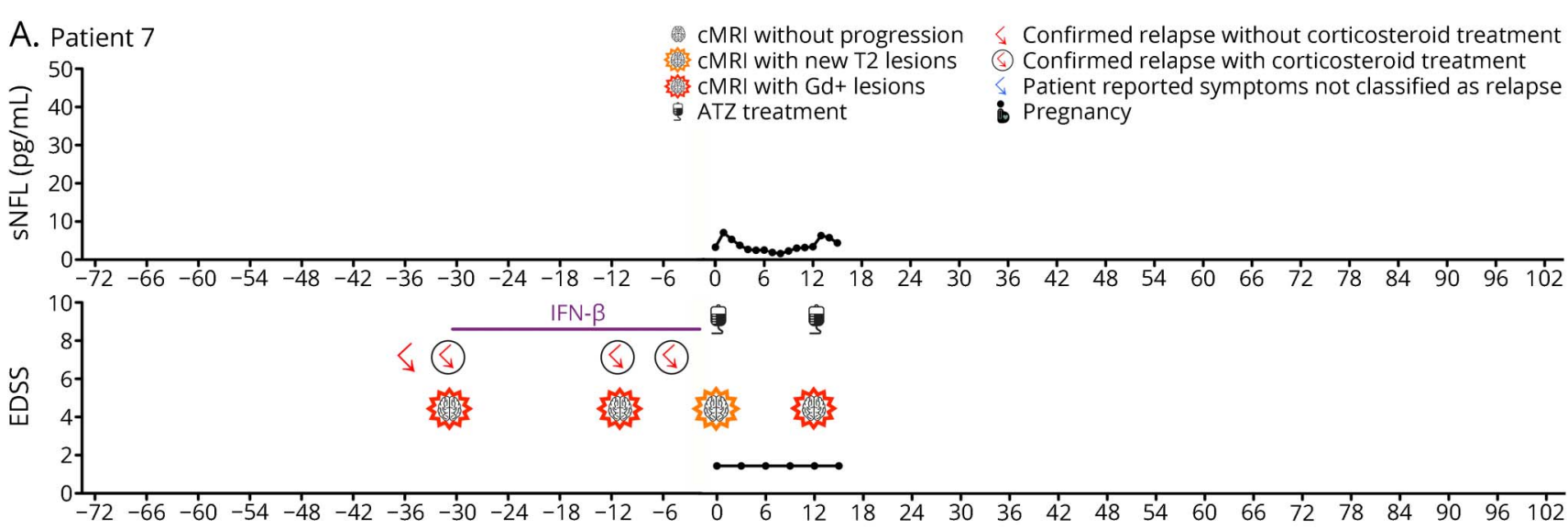

B. Patient 8

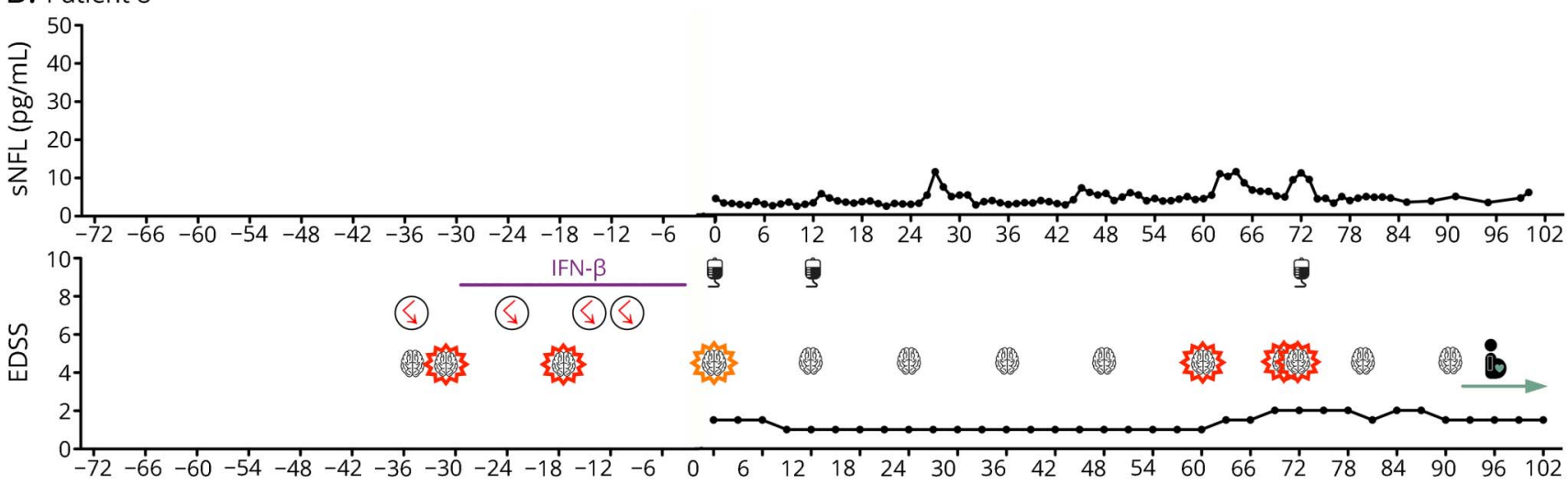

C. Patient 9

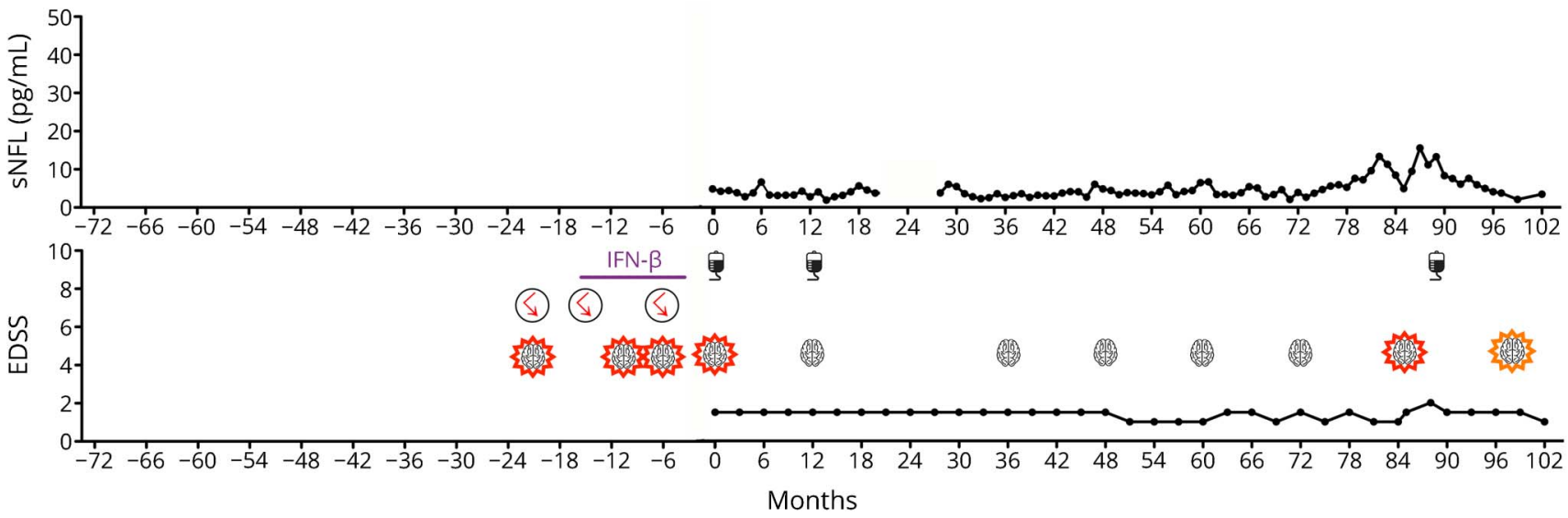

Clinical data and SNfL variation since starting ATZ and during follow-up are presented. Clinical data including relapse activity, MRI activity, and pretreatments are shown for the period before starting ATZ. Since ATZ initiation, a standardized monitoring scheme was performed by evaluation of relapse activity every months, 3 monthly EDSS, and cerebral MRI every 12 months. (patient 7) Patient 7 did receive only the first and the second ATZ infusion cycles. After 14 months, the patient moved and was lost to follow-up. Based on return of clinical and MRI disease activity, ATZ retreatment was performed in patients 8 to 15 . (patients 8-9) After ATZ initiation, patients stabilized rapidly in clinical symptoms and NEDA-3 status was reached. Years after first ATZ infusions, upcoming disease activity was presented confirmed by new $\mathrm{Gd}+$ lesions that was paralleled by the increase in $\mathrm{sNfL}$. ATZ = alemtuzumab; $\mathrm{cMRI}=\mathrm{cerebral}$ magnetic resonance imaging; Gd+ = gadolinium enhancing; NEDA = no evidence of disease activity; sNfL = serum neurofilament light chain.

$p$ values were originated from that model. For the analyses of pre-relapse phases, doses of ATZ were included as a random factor. Bonferroni correction for pairwise tests was used. Values of $p<0.05$ were considered significant. The length of the comparable time segment (CTS) for comparisons between subjects with and without relapses was set to \pm 12 months for respective analyses. The start of the
CTS will be the respective number of months prior to the first relapse of a subject or, for relapse-free subjects, under stable conditions after the second ATZ cycle (defined as 12 months after the second ATZ cycle or 24 months after the initial treatment). CTS will be individually censored in the case of other events of disease activity in the predefined segment. Figures present means and 95\% CIs. Correlation was 


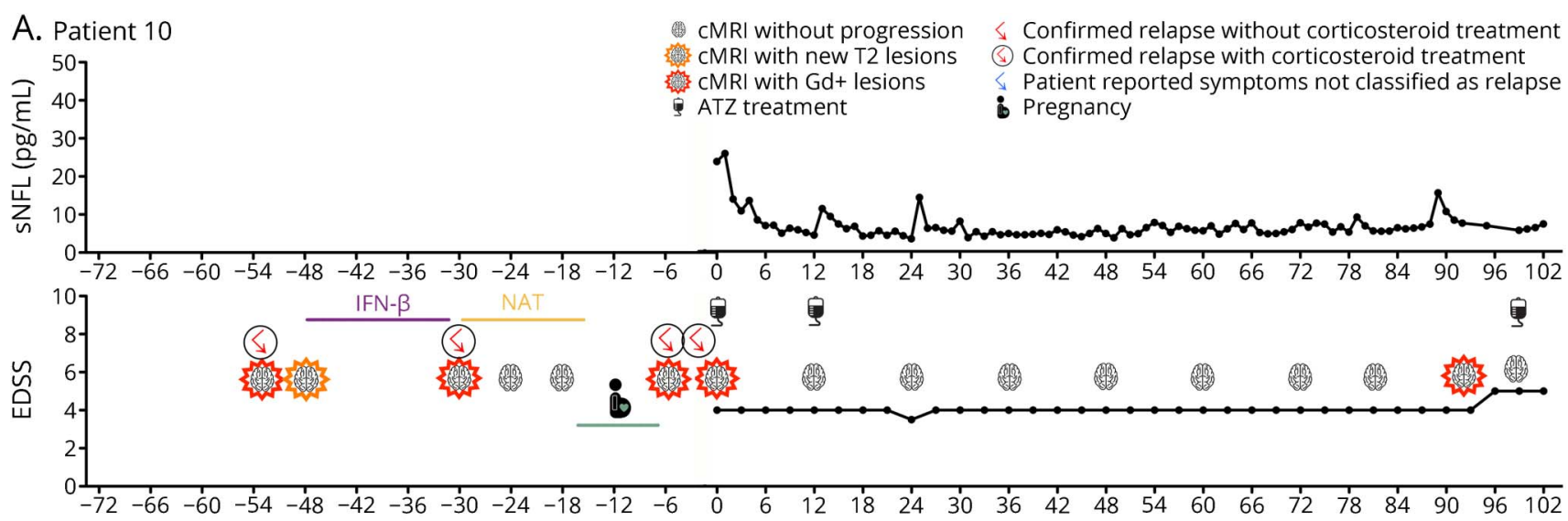

B. Patient 11

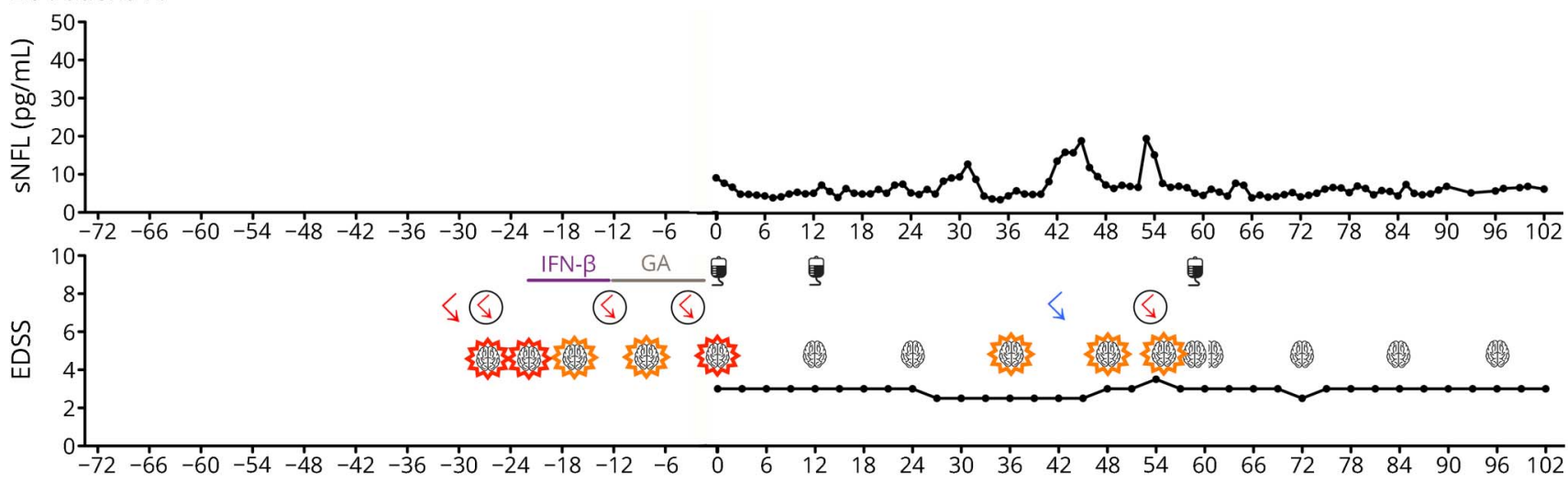

C. Patient 12

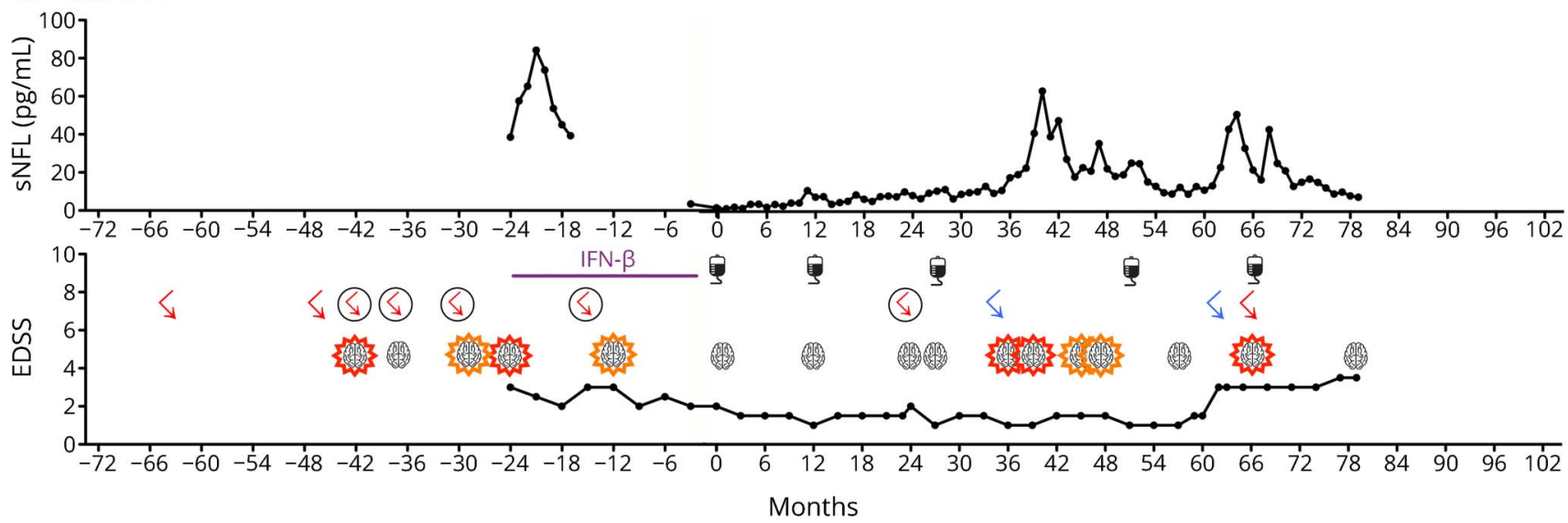

Clinical data and sNfL variation since starting ATZ and during follow-up are presented. Clinical data including relapse activity, MRI activity, and pretreatments are shown for the period before starting ATZ. Since ATZ initiation, a standardized monitoring scheme was performed by evaluation of relapse activity every months, 3 monthly EDSS, and cerebral MRI every 12 months. Based on return of clinical and MRI disease activity, ATZ retreatment was performed in patients 8 to 15. (patient 10) After ATZ initiation, patients stabilized rapidly in clinical symptoms and NEDA-3 status was reached. Years after first ATZ infusions, upcoming disease activity was presented confirmed by new Gd+ lesions that was paralleled by the increase in sNfL. (Patients 11-12) Early after starting ATZ, patients presented upcoming or ongoing disease activity paralleled by sNfL increase. ATZ = alemtuzumab; cMRI = cerebral magnetic resonance imaging; Gd+ = gadolinium enhancing; NEDA = no evidence of disease activity; sNfL = serum neurofilament light chain.

calculated using Spearman correlation test. Sensitivity and specificity of significant sNfL peaks were calculated for the period after the first and the second ATZ treatment. Starting at month 24, sNfL levels were evaluated at 3 monthly intervals and rated as normal/negative peak for levels $(\leq[$ mean $[\mathrm{SS}]+$ $[3 \times \mathrm{SD}])$ and increased/positive peak for levels $(>$ mean
$[\mathrm{SS}]+[3 \times \mathrm{SD}])$. In total, 210 of the 3 monthly intervals were evaluated while the presence of relapse activity, confirmed EDSS progression defined by increase $\geq 1.0$ for a minimum of 6 months, and MRI progression was assessed as well to define the presence of significant disease activity vs stable disease course. Statistical analyses were performed using the IBM 
A. Patient 13

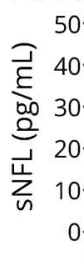

CMRI without progression CMRI with new T2 lesions 解 CMRI with Gd+ lesions

s ATZ treatment
Confirmed relapse without corticosteroid treatment (4) Confirmed relapse with corticosteroid treatment $\varangle$ Patient reported symptoms not classified as relapse is Pregnancy

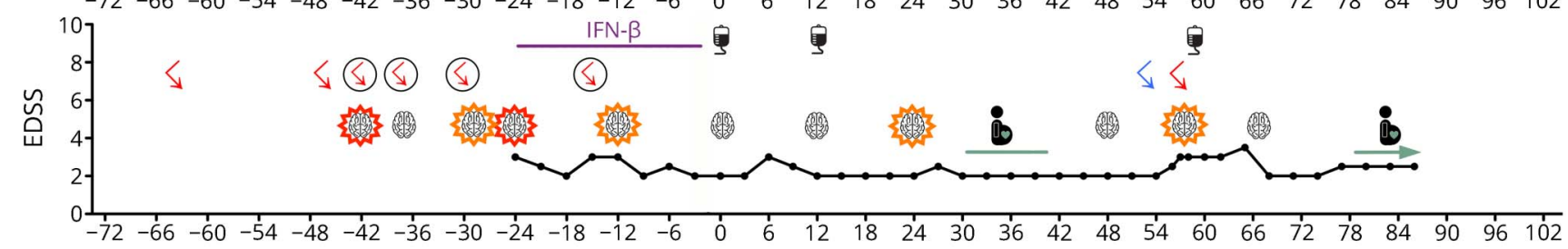

B. Patient 14

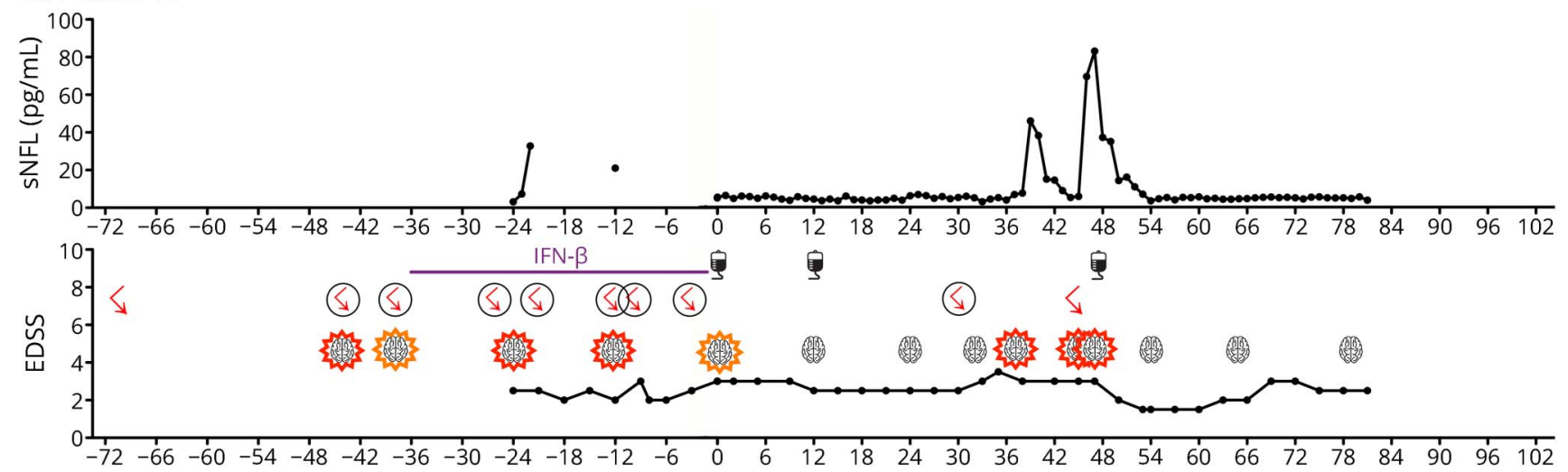

C. Patient 15

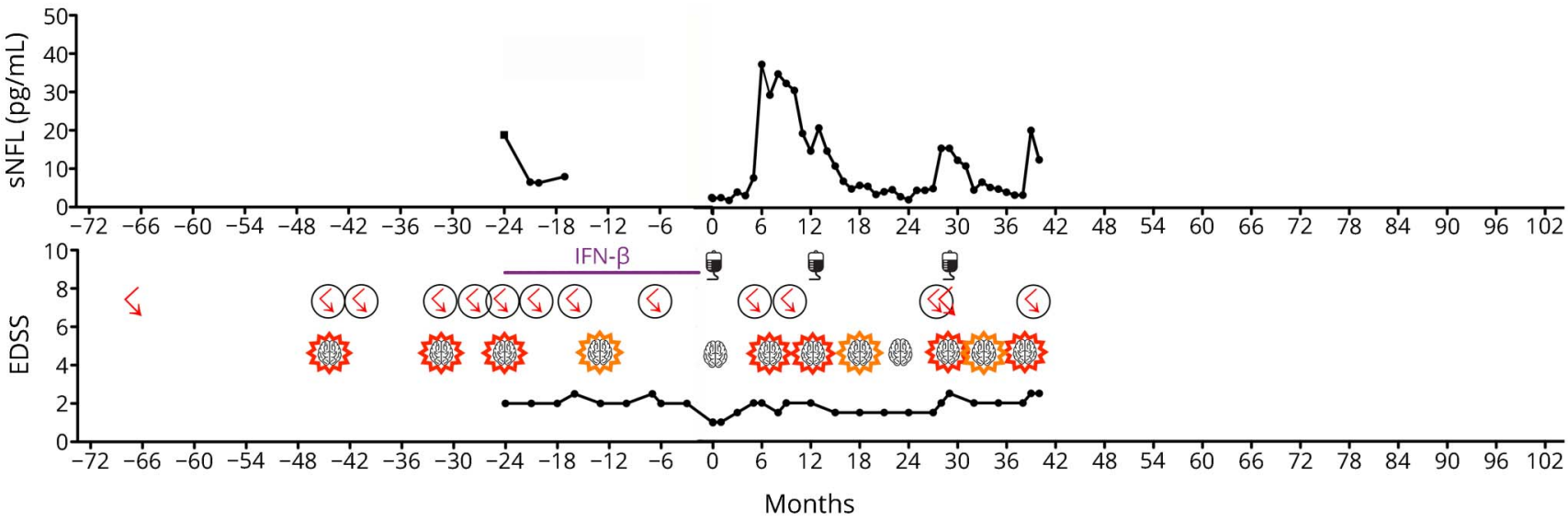

Clinical data and sNfL variation since starting ATZ and during follow-up are presented. Clinical data including relapse activity, MRI activity, and pretreatments are shown for the period before starting ATZ. Since ATZ initiation, a standardized monitoring scheme was performed by evaluation of relapse activity every months, 3 monthly EDSS, and cerebral MRI every 12 months. Based on return of clinical and MRI disease activity, ATZ retreatment was performed in patients 8 to 15 . (patients 13-15) Early after starting ATZ, patients presented upcoming or ongoing disease activity that was paralleled by the increase in sNfL. ATZ = alemtuzumab; $\mathrm{CMRI}$ = cerebral magnetic resonance imaging; Gd+ = gadolinium enhancing; NEDA = no evidence of disease activity; sNfL = serum neurofilament light chain.

SPSS software for Windows (version 25.0; IBM Corporation, Armonk, NY).

\section{Data availability}

K. Akgün and T. Ziemssen have full access to all dataset and take full responsibility for the integrity of the data and accuracy of the data analysis. Data will be shared on request from any qualified investigator.

\section{Results}

\section{sNfL baseline levels before ATZ initiation}

Individual disease course and variation in $\mathrm{sNfL}$ are depicted (figures 1-5). Immediately before starting ATZ, 6 of 15 patients presented with significantly increased sNfL levels $(21.59 \pm 10.48 \mathrm{pg} / \mathrm{mL})($ mean $\pm 95 \% \mathrm{CI})$ (table, figure e-1A, links.lww.com/NXI/A108). This was in line with MRI scans 
one week before demonstrating progression of the number of $\mathrm{T} 2$ lesions in all and new $\mathrm{Gd}+$ lesions in 5 of these patients compared to the previous MRI 12 months before. The last clinically confirmed relapse before starting ATZ occurred on average 4.2 months ago (range 1-10 months). In contrast, 9 patients presented with sNfL levels, unchanged to their SS levels (table). Here, 4 patients presented an unchanged MRI lesion load, 3 patients presented new T2 lesions, and 2 patients showed new Gd+ lesions in MRI compared to MRI 12 months before. In these patients, last relapse activity was documented a much longer time period ago, about 8.2 months (range 3-15 months). There was a strong negative correlation of sNfL increase and time interval of last relapse activity $(\mathrm{r}=-0.6018 ; p<0.05)$.

After starting ATZ, initially elevated sNfL levels constantly decreased and reached individual SS on average within 5.3 months (range 2-10 months) (table, figure e-1A, links.lww. com/NXI/A108). At the second ATZ infusion course, 2 patients presented a significant increase in sNfL levels that declined after 2 respectively 6 months (figures 2 and 5, patient 4 and 15). Interestingly, after ATZ initiation, 5 of the 15 patients presented a transient increase in $\mathrm{sNfL}$ at month $2-3$ after the first ATZ infusion and 3 of the 15 patients after the second ATZ infusion course that declined in the following months (figures 1-3, patient 3, 4, 5, 7, and 10).

Only a limited number of blood samples were available for 4 patients receiving interferon-beta therapy in the treatment period before ATZ initiation (figure 5, patient 12-15). All 4 patients presented ongoing disease activity reflected by clinical relapses and MRI progression. Increase and high intraindividual variation of sNfL levels were also seen in the clinical active period before starting ATZ with the highest sNfL level of up to $84.2 \mathrm{pg} / \mathrm{mL}$ (figure 5, patient 12).

\section{Variation of sNfL in patients with NEDA-3 status after ATZ treatment}

After receiving the first and the second ATZ standard infusion courses, all patients responded to treatment documented by decreased clinical and MRI activity. Seven of 15 patients after the first ATZ infusion course presented and one more patient after the second ATZ infusion course presented confirmed EDSS improvement $\geq 0.5$ for at least 6 months. In our cohort, 4 patients met the criteria for the NEDA-3 status even during entire 102 months of long-term follow-up (figures 1 and 2, patient 1-4). Others reached NEDA-3 status after ATZ treatment as well but presented reappearance of disease activity during the follow-up of 5 and 7 years that necessitated ATZ retreatment (figure 1, patient 8-10). When NEDA-3 was confirmed, sNfL levels reached an individual low SS level of $<8 \mathrm{pg} / \mathrm{mL}$ (table, figures 1-5).

sNFL-real-time marker for upcoming disease activity in patients with ATZ-treated MS

Although some patients met the NEDA-3 status for a long term after starting ATZ, others presented with a decreased but still ongoing or returning disease activity months or years after the first ATZ infusions. After the initial ATZ use and decrease of sNfL levels, all patients reached individual SS levels of sNfL during the stable disease period. Evaluating sNfL levels during follow-up, repeated significant sNfL peaks could be detected at different time points in some patients. After the first and the second ATZ treatment courses, a total of $34 \mathrm{sNfL}$ peaks could be identified in our patients (figure e-2A, links.lww.com/ NXI/A108). Twenty-seven sNfL peaks were associated with confirmed clinical or MRI disease activity (figure e-2A, links. lww.com/NXI/A108). In contrast, 146 of 152 of quarterly intervals without any sNfL peak were associated with stable disease (figure e-2B, links.lww.com/NXI/A108). Regarding relapses, individual sNfL levels started to increase 5 months before the first symptoms of relapse appeared (estimated means $p<0.05$ at month 5,4 , and 2 before onset of relapse) and were significantly elevated at the onset of clinical relapse activity $(p<0.001)$ (figure e-3A, links.lww.com/NXI/A108). At acute relapse activity, sNfL levels peaked to up to $81.9 \mathrm{pg} /$ $\mathrm{mL}$. After clinical onset of relapse, sNfL further increased and recovered in the following months. 95\% CI of sNfL after relapse approximated to $95 \%$ CI of NEDA-3 status patients earliest 3-month follow-up (figure e-3A, links.lww.com/NXI/ A108).

Six patients came to an unscheduled consultation reporting acute worsening and symptoms that were not confirmed as a relapse by our neurologists presenting with an sNfL peak as demonstrated by later analysis (figure e-2A, links.lww.com/ NXI/A108). These symptoms covered acute worsening of dysesthesia, paresthesia, fatigue, or dizziness and resolved spontaneously within weeks. Comparable to the confirmed relapses, sNfL started increasing 5 months before, peaked at clinical onset and within 3 months of follow-up $(p<0.013)$, and subsequently decreased after 4 months (figure e-3B, links. lww.com/NXI/A108).

Linking sNfL with MRI activity, an increase in sNfL levels was mostly associated with a progression of the $\mathrm{T} 2$ lesion load and new $\mathrm{Gd}+$ lesions as observed in 24 of 34 cases (figure e-2A, links.lww.com/NXI/A108). Yearly MRI scans demonstrated that an increase in sNfL was usually detectable already months before MRI could confirm new subclinical activity of the past 12 months. In particular, in patients with new T2 lesions but without $\mathrm{Gd}+$ lesions, the peak and increase in sNfL was seen on average 6-1 months before MRI scan was taken (figure e-3C, links.lww.com/NXI/A108). In contrast, the presentation of $\mathrm{Gd}+$ lesions was paralleled by an sNfL increase around the time point of MRI scans, reflecting the association of acute disease activity between $\mathrm{sNfL}$ peak and $\mathrm{Gd}+$ lesion in time that abated within the following 4-6 months (figure e-3D, links.lww.com/NXI/A108).

The sNfL pattern associated with disease activity was comparable with clinical and MRI activity: In contrast to our NEDA-3 patients, 95\% CI of sNfL levels of active patients increased 5 months before the clinical event, peaked within 3 
months, and decreased at about 5 months of follow-up (figure e-3E, links.lww.com/NXI/A108). Looking at our data, quarterly assessment of sNfL levels should be the minimum frequency of sNfL analysis, which seems to be necessary to detect all real-time variations in patients with MS during longterm observation.

For 7 sNfL peaks, no signs of disease activity measured by cMRI, and relapse activity or relapse-associated EDSS increase could be documented (figure e-2A, links.lww.com/NXI/ A108). In our cohort, 4 pregnancies were documented after ATZ initiation. During pregnancies, $s N f L$ was at low and stable levels (figures 1, 3, and 5, patient 3, 8, and 13). After birth, a transient sNfL increase was seen in 2 patients without any signs of clinical or MRI activity (figures 1 and 5, patient 3 and 13), and data for sNfL levels after birth are missing after 2 pregnancies (figures 3 and 5, patient 8 and 13). Five more sNfL peaks appeared at the period of stable disease that principally met the NEDA-3 status. However, conclusive comparable data on spinal MRI follow-up are missing in our study.

In addition to sNfL peaks, we searched the sNfL follow-up measurements for time intervals of 3 months with normal sNfL levels $(\leq[$ mean $[S S]+[3 \times S D])$ after ATZ initiation. In total, $210 \mathrm{sNfL}$ quarterly intervals were analyzed. For 146 intervals, stable disease without evidence of clinical or MRI progression was documented as well as sNfL was at the normal level (figure e-2B, links.lww.com/NXI/A108). For only 6 intervals, normal sNfL was paralleled by a classified relapse (1), disability progression (2), or MRI progression (3). For the remaining 58 quarterly intervals, an increase in sNfL was associated with clinical or/and MRI activity.

Evaluation of quarterly time intervals with and without sNfL peak after ATZ initiation was used to calculate sensitivity and specificity. An sNfL peak could indicate acute clinical and/or MRI disease activity in $89.47 \%$ of the cases (sensitivity). Low sNfL levels were associated without clinical or MRI disease activity in $95.42 \%$ (specificity).

\section{sNfL after ATZ retreatment}

Based on the reappearance of disease activity, ATZ retreatment was initiated in 8 patients (figures 3-5, patient 8-15). At least, $10 \mathrm{ATZ}$ retreatments $(7$ patients received $1 \mathrm{ATZ}$ retreat and 1 patient received 3 ATZ retreats) had to be performed in our cohort. During the period before ATZ retreatment, which was characterized by upcoming disease activity as demonstrated by relapse or MRI progression, sNfL levels showed a prolonged increase (figure e-1B, links.lww.com/NXI/ A108). In 6 patients, ATZ retreat led to a rapid decrease in clinical disease activity and stable disease since retreat in longterm follow-up. sNfL decreased and reached a low SS level on average of 4.2 months (figure e-1B, links.lww.com/NXI/ A108). Although clinical and MRI activity decreased after ATZ retreatment in 2 patients, it did not led to a completely stable disease, which was reflected again by increased sNfL levels (figure 5, patient 12, 15).

\section{Discussion}

The evaluation of $\mathrm{sNfL}$ is a promising opportunity to evaluate MS disease activity. While measurement of NfL in CSF has already demonstrated a significant correlation with inflammatory disease activity, ${ }^{12-14}$ fourth-generation immunoassays allow the implementation of sNfL measurement from patients ' blood as "easy-to-measure" marker to reflect acute neuroaxonal damage. Of particular interest is the proof that sNfL levels can be used to separate not only patients with MS from healthy controls but also to separate patients with MS with and without persistent clinical and subclinical MRI disease activity. ${ }^{19,29,30}$ In previous studies, increased sNfL levels in patients with MS have been independently associated with disability and relapse status and suggested to be a predictive marker for future relapses and disability worsening. ${ }^{17,19}$ Further data have proved that patients on disease-modifying treatment had lower sNfL levels than untreated patients. ${ }^{29}$ In this line, another study found that patients who switched from injectable therapies to fingolimod had significantly lower sNfL levels than staying on injectables. ${ }^{31}$ Associations between disease activity and treatment-related reductions in sNfL levels were confirmed by another study in a large independent cohort of patients with relapsing-remitting MS. ${ }^{11}$ A longitudinal observational study demonstrated that patients with increased sNfL levels at baseline, independent of other clinical and MRI variables, experienced significantly more brain and spinal cord volume loss over 2 and 5 years of follow-up. ${ }^{17}$ Nevertheless, detailed data on high-frequency measurements of sNfL levels in patients with MS are still missing. This could assist their implementation into clinical practice by profiling individual sNfL dynamics during active vs stable disease. This is especially interesting for patients treated with immune reconstitution therapies as ATZ. Different response profiles to ATZ have been described so far, ${ }^{32}$ which only were defined by clinical characteristics as relapse activity and disability as well as repeated MRI analysis. 5,6

In this pilot study, we analyzed the individual variation of sNfL levels using monthly measurements in patients with relapsing-remitting MS over a long period. Our 15 patients were treated with ATZ, which mediates its long-term efficacy by depleting $\mathrm{T}$ and $\mathrm{B}$ lymphocyte subsets and immunereconstitution during follow-up. The definition of treatment response and the resulting potential need for retreatment are important aspects in ATZ therapy. However, careful evaluation of clinical and MRI response profiles in ATZ-treated patients combined with high-frequency measurement of sNfL levels is a straightforward approach to learn more about sNfL in the follow-up of patients with MS.

In parallel with the highly active disease course, which was the reason to treat with ATZ, increased sNfL levels were documented before starting ATZ, which declined after ATZ infusion within the following months. Even high-frequency sNfL assessment could prove the positive long-term treatment effect of only 2 ATZ courses mostly. During stable 
disease, a low individual SS level of sNfL without significant variations was found. In the period after ATZ treatment, our data indicate that sNfL increase is clearly associated with the return of clinical and MRI disease activity. In particular, relapse activity and development of new $\mathrm{Gd}+$ lesions were paralleled by an increase in sNfL. The peak in sNfL levels was directly linked with the onset of relapse and acute MRI activity. High-frequency evaluation of sNfL could demonstrate that the increase in sNfL already starts several months before relapse activity is clinically visible. Nevertheless, the sample size in our pilot study group is too small to draw final conclusions on the exact time period when sNfL peak is predictive for disease activity. Interestingly, patient-reported symptoms that have not been classified as clinical relapse by the treating neurologists have been sometimes associated with an sNfL increase, proposing acute sNfL assessment as a parameter to identify real relapse activity in patients with MS. Although the number of patients is limited in this pilot evaluation, the estimation on sensitivity and specificity proposed high quality in the classification of active vs stable disease using sNfL measures. Previous studies have evaluated the relationship of sNfL levels with clinical and MRI data at the group level. ${ }^{11,19,29}$ Only a few reports are available that assess sNfL levels during follow-up, but using low-frequency assessment periods of a year. ${ }^{11,31}$ Our high-frequency sNfL assessment is capable to document the dynamics of sNfL peaks as increases for a short time period of 3-6 months, which are associated with disease activity. Our data demonstrate that at the minimum quarterly sNfL measurements would be sufficient to detect all real-time variations during long-term observation. A monthly assessment of sNfL does not seem to be necessary as performed in our high-frequency study.

During our observation, few sNfL peaks could be seen in patients without evidence of MS disease activity as measured by relapses, disability progression, or MRI activity. Usually, sNfL levels were at their lowest level at the period when the NEDA-3 status was confirmed. However, only cerebral MRI was performed in our study, whereas conclusive longitudinal data on spinal MRI were not available. Other studies already confirmed the correlation between increased sNfL levels and $\mathrm{Gd}+$ spinal lesions as well as brain and spinal cord atrophy, ${ }^{11,17,18}$ which were not evaluated in our study as well. In our cohort, there were no other reported events as trauma episodes, stroke, anesthesia during surgery, or metabolic diseases that were supposed to be associated with sNfL increase. ${ }^{33-36}$ However, we are not able to completely exclude such factors. In MS, sNfL peaks can indicate subclinical disease activity even when clinical parameters and cerebral MRI seem to be stable. Further studies are necessary to investigate the relevance of additional MRI parameters to confirm active vs stable disease.

Several studies highlighted the relevance of sNfL levels to reflect ongoing neuroinflammation as well as neurodegeneration in patients with MS. ${ }^{8,37}$ In our cohort, only patients with highly active relapsing-remitting MS disease course were included.
Instability and increase in sNfL level were clearly associated with relapses and occurrence of new $\mathrm{T} 2$ and $\mathrm{Gd}+$ lesions in cerebral MRI that are typically linked to the inflammatory characteristics of MS pathology. Our data represent sNfL as a real-time marker of current or upcoming inflammatory disease activity as well as treatment response on an individual level rather than only a predictive parameter for disease outcome in patients with relapsing-remitting MS at the group level. Collection of real-world data and observational studies providing longitudinal information on drug profile and different outcomes in real life are essential to derive more and important implications for sNfL use in clinical practice. ${ }^{38-40}$

Here, we present long-term high-frequency sNfL assessments in an ATZ-treated cohort for up to 8.5 years of follow-up, allowing a holistic clinical, MRI, and sNfL responder evaluation on the individual patient level. sNfL can complement the individual clinical and MRI monitoring after immune reconstitution treatment with ATZ. More long-term data regarding individual sNfL patient profiles have to be generated for different treatment options before sNfL could become a key parameter for decision-making in clinical practice.

\section{Author contributions}

Study concept and design: K. Akgün and T Ziemssen. Acquisition of data: K. Akgün, N Kretschmann, U Proschmann, H.H. Kitzler. Analysis and interpretation of data: K. Akgün, R. Haase. Drafting of the manuscript: K. Akgün and T. Ziemssen. Critical revision of the manuscript for important intellectual content: N. Kretschmann, U. Proschmann, H. Kitzler, H. Reichmann. Statistical analysis: R. Haase, K. Akgün. Study supervision: T. Ziemssen.

\section{Acknowledgment}

The authors thank M. Marggraf and N. Dartsch for technical assistance.

\section{Study funding}

Not applicable.

\section{Disclosure}

K. Akgün received honoraria from Sanofi for consulting and speaking service. T. Ziemssen received personal compensation from Sanofi for consulting services and financial support for research activities from Sanofi. H. H. Kitzler received honoraria from Sanofi for speaking service N. Kretschmann, R. Haase, U. Proschmann, and $\mathrm{H}$. Reichmann declare no competing interest. Disclosures available: Neurology.org/NN.

\section{Publication history}

Received by Neurology: Neuroimmunology \& Neuroinflammation December 19, 2018. Accepted in final form January 28, 2019.

\section{References}

1. Kalincik T, Brown JWL, Robertson N, et al. Treatment effectiveness of alemtuzumab compared with natalizumab, fingolimod, and interferon beta in relapsing-remitting multiple sclerosis: a cohort study. Lancet Neurol 2017;16:271-281. 
2. Hassoun LEJ, Thomas K, Ziemssen T. Hands on Alemtuzumab-experience from clinical practice: whom and how to treat. Mult Scler Demyelinating Disord 2016; 1: 10.

3. Ziemssen T, Thomas K. Alemtuzumab in the long-term treatment of relapsingremitting multiple sclerosis: an update on the clinical trial evidence and data from the real world. Ther Adv Neurol Disord 2017;10:343-359.

4. D'Amico E, Ziemssen T, Cottone S. Induction therapy for the management of early relapsing forms of multiple sclerosis: a critical opinion. Expert Opin Pharmacother 2017;18:1553-1556.

5. Ziemssen T, Thomas K. Treatment optimization in multiple sclerosis: how do we apply emerging evidence? Expert Rev Clin Immunol 2017;13:509-511.

6. Ziemssen T, Derfuss T, de Stefano N, et al. Optimizing treatment success in multiple sclerosis. J Neurol 2016;263:1053-1065.

7. Ziemssen T, Kern R, Thomas K. Multiple sclerosis: clinical profiling and data collection as prerequisite for personalized medicine approach. BMC Neurol 2016;16:124.

8. Khalil M, Teunissen CE, Otto M, et al. Neurofilaments as biomarkers in neurological disorders. Nat Rev Neurol 2018;14:577-589.

9. Bergman J, Dring A, Zetterberg H, et al. Neurofilament light in CSF and serum is a sensitive marker for axonal white matter injury in MS. Neurol Neuroimmunol Neuroinflamm 2016;3:e271. doi: 10.1212/NXI.0000000000000271.

10. Teunissen CE, Khalil M. Neurofilaments as biomarkers in multiple sclerosis. Mult Scler 2012;18:552-556.

11. Disanto G, Barro C, Benkert P, et al. Serum Neurofilament light: a biomarker of neuronal damage in multiple sclerosis. Ann Neurol 2017;81:857-870.

12. Hakansson I, Tisell A, Cassel P, et al. Neurofilament light chain in cerebrospinal fluid and prediction of disease activity in clinically isolated syndrome and relapsingremitting multiple sclerosis. Eur J Neurol 2017;24:703-712.

13. Bhan A, Jacobsen C, Myhr KM, Dalen I, Lode K, Farbu E. Neurofilaments and 10-year follow-up in multiple sclerosis. Mult Scler 2018;24:1301-1307.

14. van der Vuurst de Vries RM, Wong YYM, Mescheriakova JY, et al. High neurofilament levels are associated with clinically definite multiple sclerosis in children and adults with clinically isolated syndrome. Mult Scler Epub 2018 May 1.

15. Petzold A. The prognostic value of CSF neurofilaments in multiple sclerosis at 15 -year follow-up. J Neurol Neurosurg Psychiatry 2015;86:1388-1390.

16. Disanto G, Adiutori R, Dobson R, et al. Serum neurofilament light chain levels are increased in patients with a clinically isolated syndrome. J Neurol Neurosurg Psychiatry 2016;87:126-129.

17. Barro C, Benkert P, Disanto G, et al. Serum neurofilament as a predictor of disease worsening and brain and spinal cord atrophy in multiple sclerosis. Brain 2018;141: 2382-2391.

18. Kuhle J, Nourbakhsh B, Grant D, et al. Serum neurofilament is associated with progression of brain atrophy and disability in early MS. Neurology 2017;88: 826-831.

19. Siller N, Kuhle J, Muthuraman M, et al. Serum neurofilament light chain is a biomarker of acute and chronic neuronal damage in early multiple sclerosis. Mult Scler Epub 2018 Mar 1.

20. Caon C, Namey M, Meyer C, et al. Prevention and management of infusionassociated reactions in the comparison of alemtuzumab and rebif $((\mathrm{R}))$ efficacy in multiple sclerosis (CARE-MS) program. Int J MS Care 2015;17:191-198.

21. Cohen JA, Coles AJ, Arnold DL, et al. Alemtuzumab versus interferon beta 1 a as firstline treatment for patients with relapsing-remitting multiple sclerosis: a randomised controlled phase 3 trial. Lancet 2012;380:1819-1828.
22. Coles AJ, Twyman CL, Arnold DL, et al. Alemtuzumab for patients with relapsing multiple sclerosis after disease-modifying therapy: a randomised controlled phase 3 trial. Lancet 2012;380:1829-1839.

23. Giovannoni G, Tomic D, Bright JR, Havrdova E. No evident disease activity: the use of combined assessments in the management of patients with multiple sclerosis. Mult Scler 2017;23:1179-1187.

24. Kuhle J, Plattner K, Bestwick JP, et al. A comparative study of CSF neurofilament light and heavy chain protein in MS. Mult Scler 2013;19:1597-1603.

25. Keshavan A, Heslegrave A, Zetterberg H, Schott JM. Stability of blood-based biomarkers of Alzheimer's disease over multiple freeze-thaw cycles. Alzheimers Dement (Amst) 2018;10:448-451.

26. Wilson DH, Rissin DM, Kan CW, et al. The Simoa HD-1 analyzer: a novel fully automated digital immunoassay analyzer with single-molecule sensitivity and multiplexing. J Lab Autom 2016;21:533-547.

27. Petzold A, Altintas A, Andreoni L, et al. Neurofilament ELISA validation. J Immunol Methods 2010;352:23-31.

28. Kuhle J, Barro C, Andreasson U, et al. Comparison of three analytical platforms for quantification of the neurofilament light chain in blood samples: ELISA, electrochemiluminescence immunoassay and Simoa. Clin Chem Lab Med 2016;54 1655-1661.

29. Novakova L, Zetterberg H, Sundström P, et al. Monitoring disease activity in multiple sclerosis using serum neurofilament light protein. Neurology 2017;89:2230-2237.

30. Kuhle J, Barro C, Disanto G, et al. Serum neurofilament light chain in early relapsing remitting MS is increased and correlates with CSF levels and with MRI measures of disease severity. Mult Scler 2016;22:1550-1559.

31. Piehl F, Kockum I, Khademi M, et al. Plasma neurofilament light chain levels in patients with MS switching from injectable therapies to fingolimod. Mult Scler 2018; 24:1046-1054.

32. Wiendl H, Calabresi PA, Meuth SG. Defining response profiles after alemtuzumab: rare paradoxical disease exacerbation. Neurology 2018;90:309-311.

33. Evered L, Silbert B, Scott DA, Zetterberg H, Blennow K. Association of changes in plasma neurofilament light and tau levels with anesthesia and surgery: results from the CAPACITY and ARCADIAN studies. JAMA Neurol 2018;75:542-547.

34. Kuhle J, Gaiottino J, Leppert D, et al. Serum neurofilament light chain is a biomarker of human spinal cord injury severity and outcome. J Neurol Neurosurg Psychiatry 2015;86:273-279.

35. Shahim P, Zetterberg H, Tegner Y, Blennow K. Serum neurofilament light as a biomarker for mild traumatic brain injury in contact sports. Neurology 2017;88:1788-1794.

36. Pujol-Calderon F, Portelius E, Zetterberg H, Blennow K, Rosengren LE, Hoglund K. Neurofilament changes in serum and cerebrospinal fluid after acute ischemic stroke. Neurosci Lett 2018;698:58-63.

37. Khalil M. Are neurofilaments valuable biomarkers for long-term disease prognostication in MS? Mult Scler 2018;24:1270-1271.

38. Ziemssen T, Hillert J, Butzkueven $\mathrm{H}$. The importance of collecting structured clinical information on multiple sclerosis. BMC Med 2016;14:81.

39. Ziemssen T, Engelmann U, Jahn S, et al. Rationale, design, and methods of a noninterventional study to establish safety, effectiveness, quality of life, cognition, healthrelated and work capacity data on Alemtuzumab in multiple sclerosis patients in Germany (TREAT-MS). BMC Neurol 2016;16:109.

40. Haase R, Wunderlich M, Dillenseger A, Kern R, Akgün K, Ziemssen T. Improving multiple sclerosis management and collecting safety information in the real world: the MSDS3D software approach. Expert Opin Drug Saf 2018;17:369-378. 


\section{Neurology \\ Neuroimmunology \& Neuroinflammation}

\section{Profiling individual clinical responses by high-frequency serum neurofilament assessment in MS}

Katja Akgün, Nicole Kretschmann, Rocco Haase, et al.

Neurol Neuroimmunol Neuroinflamm 2019;6;

DOI 10.1212/NXI.0000000000000555

This information is current as of April 8, 2019

\section{Updated Information \& \\ Services}

References

Citations

Subspecialty Collections

Permissions \& Licensing

Reprints including high resolution figures, can be found at:

http://nn.neurology.org/content/6/3/e555.full.html

This article cites 38 articles, 3 of which you can access for free at: http://nn.neurology.org/content/6/3/e555.full.html\#\#ref-list-1

This article has been cited by 2 HighWire-hosted articles: http://nn.neurology.org/content/6/3/e555.full.html\#\#otherarticles

This article, along with others on similar topics, appears in the following collection(s):

Diagnostic test assessment

http://nn.neurology.org//cgi/collection/diagnostic_test_assessment_ Multiple sclerosis

http://nn.neurology.org//cgi/collection/multiple_sclerosis Outcome research

http://nn.neurology.org//cgi/collection/outcome_research

Information about reproducing this article in parts (figures,tables) or in its entirety can be found online at:

http://nn.neurology.org/misc/about.xhtml\#permissions

Information about ordering reprints can be found online: http://nn.neurology.org/misc/addir.xhtml\#reprintsus

Neurol Neuroimmunol Neuroinflamm is an official journal of the American Academy of Neurology.

Published since April 2014, it is an open-access, online-only, continuous publication journal. Copyright Copyright (C) 2019 The Author(s). Published by Wolters Kluwer Health, Inc. on behalf of the American Academy of Neurology.. All rights reserved. Online ISSN: 2332-7812.

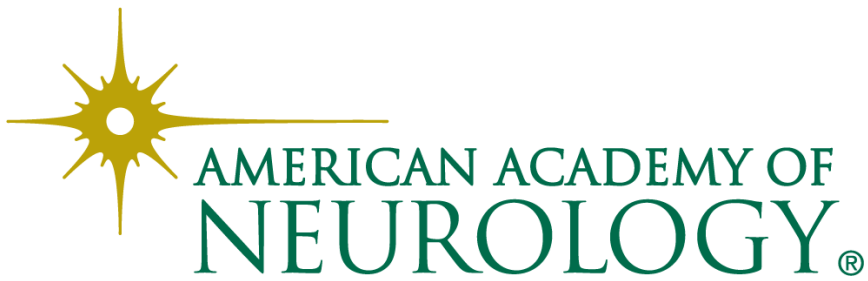

